\title{
Effect of Eight Weeks of Cardiac Rehabilitation Training on PPAR- $\alpha$ Gene Expression in CABG Patients
}

\author{
Babisan Askari (PhD) \\ Department of Physical Education and \\ Sport Sciences, Islamic Azad \\ University, Qaemshahr Branch, \\ Qaemshahr, Iran \\ Amir Rashidlamir (PhD) \\ Department of Exercise Physiology, \\ Faculty of Physical Education and \\ Sport Sciences, Ferdowsi University of \\ Mashhad, Mashhad, Iran \\ Asra Askari (PhD) \\ Department of Physical Education and \\ Sport Sciences, Islamic Azad \\ University, Gorgan Branch, Gorgan, \\ Iran \\ Masoumeh Habibian (PhD) \\ Department of Physical Education and \\ Sport Sciences, Islamic Azad \\ University, Qaemshahr Branch, \\ Qaemshahr, Iran \\ Arash Saadatniya (PhD) \\ Department of Exercise Physiology, \\ Faculty of Physical Education and \\ Sport Sciences, Shahid Beheshti \\ University, Tehran, Iran \\ Corresponding author: Babisan \\ Askari \\ Email: babisan.askari@gmail.com \\ Tel: +989111564238 \\ Address: Department of Physical \\ Education and Sport Sciences, Islamic \\ Azad University, Qaemshahr Branch, \\ Qaemshahr, Iran \\ Received : 27 Feb 2016 \\ Revised: 01 Mar 2016 \\ Accepted: 09 Mar 2016 \\ Babisan Askari https://orcid.org/0000-0002-9411- \\ 8549
}

ABSTRACT

Background and objectives: Cardiovascular disease is the leading cause of death worldwide. This study examined the effects of cardiac rehabilitation exercise on lipid profile and expression of peroxisome proliferator-activated receptor alpha (PPAR- $\alpha$ ) gene in patients who underwent coronary artery bypass grafting.

Methods: In this quasi-experimental study, after screening, patients who underwent coronary artery bypass grafting (CABG) were randomly divided into an experimental group $(\mathrm{n}=12)$ and a control group $(\mathrm{n}=12)$. After the surgery and discharge from hospital, the experimental group performed rehabilitation exercise for two months, while the control group did not perform any exercise after discharge from the hospital and the initial phase of rehabilitation. Fasting blood samples were collected before and after the last training session to evaluate biochemical variables and PPAR- $\alpha$ gene expression of lymphocytes. PPAR- $\alpha$ expression level was assessed by qRT-PCR. Statistical analysis was done in the SPSS software (version 20) using repeated measures.

Results: In the follow-up after the two-month cardiac rehabilitation exercise, the PPAR- $\alpha$ gene was significantly overexpressed and plasma HDL levels increased significantly in the training group compared with the control group $(\mathrm{P}<0.05)$. Although the concentrations of LDL and triglycerides decreased in the experimental group, this reduction was not statistically significant $(\mathrm{P}>0.05)$.

Conclusion: The results indicate that the protocols carried out in the study could be utilized for improving HIDL levels and cardiovascular function in CABG patients.

keywords: Cardiac Rehabilitation, Gene Expression, PPAR- $\alpha$. 


\section{INTRODUCTION}

Buildup of cholesterol and triglycerides (TGs) and decreased HDL-C levels are the risk factors for developing atherosclerosis. Moreover, a sedentary lifestyle exacerbates the risk of the disease. Epidemiological studies on weight loss with diet and exercise, suggest that a unit increase in HDL-C and decrease in LDL-C help improve the function of the cardiovascular system and prevent cardiovascular disease. HDL particles have antioxidant and anti-inflammatory properties and are effective in the prevention of cardiovascular disease through the reverse cholesterol transport (1).

The reverse cholesterol transport is a HDLmediated process in which excess cholesterol from peripheral tissues, including arterial wall macrophages is returned to the liver (2). Since low HDL level is usually a risk factor for atherosclerosis, raising the HDL level and its positive effects on coronary heart disease have always been the subjects of attention. Lifestyle changes such as regular exercise, quitting smoking, weight loss and a diet low in saturated fatty acids could help the elevated HDL levels (3). Peroxisome proliferationactivated receptors (PPARs) are the members of nuclear receptors family that bind to fatty acids, regulate gene expression and determine the cell fate (4). Activating PPAR-ainitiates expression of key genes involve in the HDL metabolism and reverse cholesterol transport (5).

Although studies have shown that physical activity can improve some key aspects of the reverse cholesterol transport (6), there are currently few studies on the impact of physical activity on the expression of receptor gene PPAR- $\alpha$. It can be the upstream against the process of reverse cholesterol transport and a key factor in metabolism and maturation of HDL-C particle $(7,8)$.

Recent studies show that physical activity increases HDL particle size and make them more buoyant. Exercise may also increase apolipoprotein composition, which would facilitate the reverse cholesterol transport process (9). This study investigated the role of exercise on the PPAR- $\alpha$ gene expression using a quasi-experimental design. We also examined possible protecting effects of exercise on coronary artery bypass graft surgery (CABG) patients via reverse cholesterol transport pathway.

\section{MATERIAL AND METHODS}

The study was conducted with a quasiexperimental design and a control group. The participants were selected via convenient sampling from patients who underwent $\mathrm{CABG}$ (at least one month after surgery) and they were homogeneous in terms of disease severity and physical fitness. Exclusion criteria included having permanent defibrillator/pacemaker, heart failure, history of hernia or aneurysm disease, history of regular exercise and physical disabilities that limit treadmill workouts or ergometer. After screening, the participants were randomly divided into a control group $(\mathrm{n}=12$, age: $52.83 \pm 1.33$ years) and a rehabilitation group $(\mathrm{n}=12$, age: $54.66 \pm 1.30$ years $)$. The study received approval from the ethics committee of Javadolaemeh Hospital in Mashhad. Written consent was taken from all participants of the study.

Twenty-four hours before the first training session and 48 hours after the last training session, $10 \mathrm{cc}$ fasting blood samples was taken from the brachial vein of each participant. Sampling took place at 8 o'clock and ended at 9:30 am. Dietary recommendations were given to all the participants for the night before the sampling. Part of the blood samples were collected in test tubes with EDTA for the gene expression experiment, and later transferred to biotechnology laboratory of Ferdowsi University of Mashhad. Isolation of lymphocytes was carried out by the Ficoll method. To measure the biochemical variables, tubes containing the samples and EDTA were centrifuged at 3000 RPM for 10 min. HDL-C, LDL-C, and TG levels were measured using standard kits (Parsazmun Co., Iran).

In this study, total RNA was extracted using guanidine thiocyanate kit (Roche, Germany). Next, $1 \mu \mathrm{g}$ of RNA was separated for cDNA synthesis using oligo (dT) primers and the AccuPower ${ }^{\circledR}$ RocketScript TM RT (Bioneer, Korea). Relative expression of the PPAR- $\alpha$ gene was calculated via qRT -PCR method (QIAGEN), with a TaqMan probe. Thermocycling conditions were as follows: initial denaturation at $95{ }^{\circ} \mathrm{C}$ for five minutes, followed by 40 cycles of denaturation, and annealing at $55^{\circ} \mathrm{C}$ for 20 seconds. Device was set at the extension stage for reading the fluorescence signal. PCR reactions were performed in triplicate in a final volume of 20 
$\mu 1$. Finally, PPAP- $\alpha$ mRNA expression relative to GAPDH was obtained. Sequence of the primers used in the study is shown in table 1.

Circular rehabilitation program began four weeks after the surgery and lasted two months. Weekly training program consisted three onehour sessions of aerobic training with treadmill and stationary cycling with handy ergometer. In addition to monitoring heart rate, before each session, electrocardiogram was performed for each participant. The Borg rating of perceived exertion was used to control exercise intensity (10).

Before the first session, concept of the Borg rating was explained to the participants and they were asked to keep the intensity rate between 11 (relatively light) and 13 (relatively hard). First, the rehabilitation group became familiar with the devices and trainings, and then exercised three times a week for two months. Each training session included a 5minute warm-up, 15 minutes of brisk walking on treadmill, 10 minutes of stationary cycling, and finally 10 minutes of training with the handy ergometer. A 3-minute non-active rest was given between each training sets. Blood pressure of the participants was examined continuously via the Borg scale. The control group performed no physical activity for two months.

Data was analyzed using descriptive statistics, including mean and standard deviation (SD). Considering the normality of data, repeated measurement was used to compare variances between the groups. All statistical analyses were performed in SPSS (version 20).

Table 1- Sequence of the primers used in PCR experiment

\begin{tabular}{ll}
\hline Primer & Sequence \\
\hline Hum-GAPDH-F & 5'-GGAAGGTGAAGGTCGGAGTC-3' \\
Hum-GAPDH-R & 5'-CGTTCTCAGCCTTGACGGT-3' \\
Hum- PPAP- $\alpha-F$ & 5'-CGCGTGTGATAAAGCCATTG-3' \\
Hum- PPAP- $\alpha-\mathrm{R}$ & 5'-CACGATGCTGTCCTCCTTGA-3' \\
\hline
\end{tabular}

\section{RESULTS}

The expression of the PPAR- $\alpha$ gene was significantly higher in the training group compared to the control group $(\mathrm{P}=0.0006$, $\mathrm{F}=19.407)$. The level of HDL-C increased significantly in the training group $(\mathrm{P}=0.034$,
$\mathrm{F}=5.520)$. In addition, the level of LDL-C $(\mathrm{P}=0.191, \quad \mathrm{~F}=1.890)$ and $\mathrm{TG} \quad(\mathrm{P}=0.113$, $\mathrm{F}=1.611$ ) reduced in the training group, but there was no significant difference in the level of these parameters between the two groups (Table 2).

Table 2- Comparison of dependent variables between the two groups before and after the training intervention

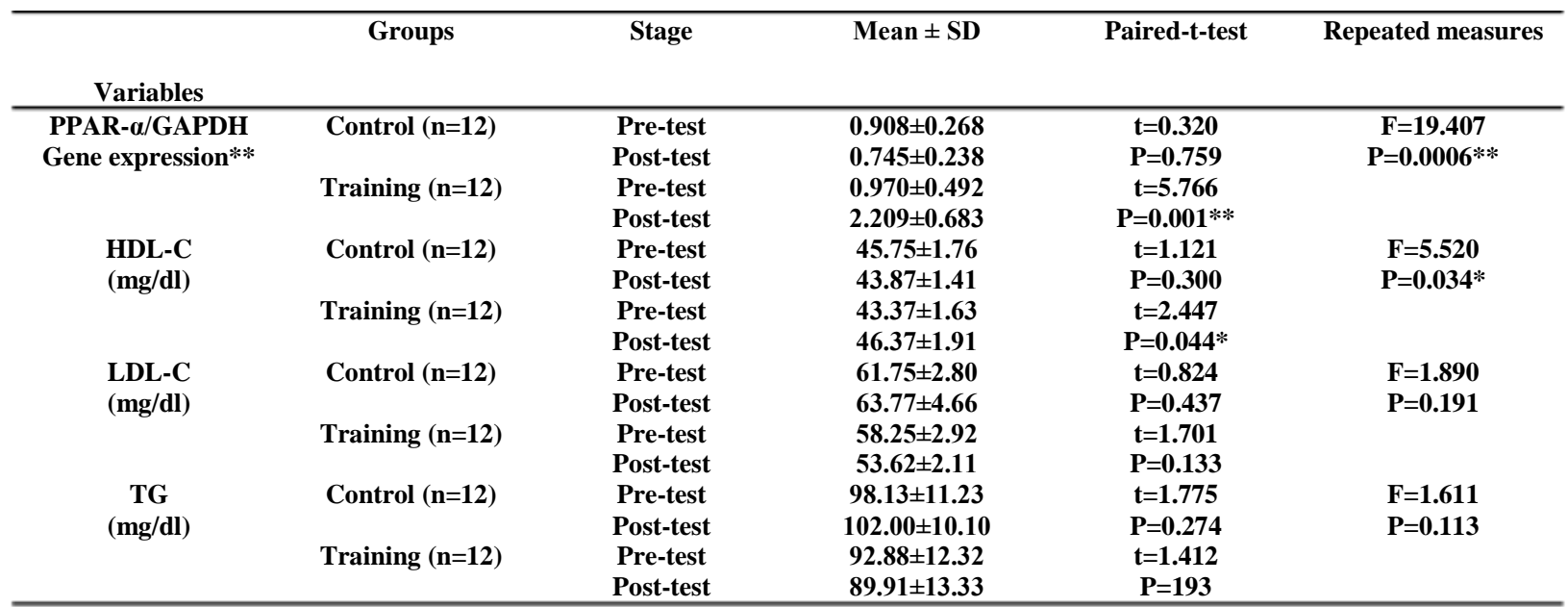

* Statistically significant $\mathbf{P}<0.05, * *$ statistically significant $\mathbf{P}<0.001$ 


\section{DISCUSSION}

The main finding of this study was the significant overexpression of the PPAR- $\alpha$ gene in lymphocytes of cardiac rehabilitation patients following eight weeks of training. A number of fundamental articles have evaluated PPAR- $\alpha$ gene expression in various tissues of animals and humans, but there is limited number of studies available on the effects of exercise on the expression level of this gene. Elevation of HDL-C level has an important role in the reverse cholesterol transport. Previous studies have shown that PPARs play a key role in two physiological functions, controlling capacity of fatty acids $\beta$-oxidation and the reverse cholesterol transport (11).

McNeil et al. investigated the effect of rehabilitation exercise combined with muscle rehabilitation on the capacity of the mitochondrial biogenesis. In the mentioned study, after spending two weeks in knee casts, 18 young participants performed combined resistance and endurance exercise for six weeks, three days a week. Their results showed a significant increase in the expression of genes involved in mitochondrial biogenesis (PGC- $1 \alpha$, PRC, PPAR- $\alpha$ ) and the capacity of the electron transport chain (12). Similar findings were reported by Tantalite al. regarding the effects of nine days of cycling on factors affecting fatty acid $\beta$-oxidation, including PPAR- $\alpha$ (13).

Regarding the effect of physical activity on lipid profile, a study by Schwartz et al. showed that six months of intensive endurance training (5 days a week) significantly increases HDL-C level in healthy young and old men. Moreover, a non-significant decrease in TG and LDL-C to HDL-C ratio was also observed in the older cases (14). Similar results were reported in study of Park et al. on obese middle-aged women (15).

Although it has been suggested that combination of aerobic/resistance exercise significantly increases PPAR- $\alpha$ expression after six months, in our study, this effect on the gene expression was achieved after only eight weeks (16). Boucher et al. reported that eight weeks of low-intensity exercise upregulates expression of leukocytes' LXR and PPAR genes. They also suggested that this overexpression promotes the reverse cholesterol transport through activity of PPAR ligands in initial activation of LXR. In addition, LXR-mediated overexpression of transporters involved in the reverse cholesterol transport. They also suggested that exercise would increase plasma concentrations of HDL-C and decrease LDL-C levels compared to control group (7). A review on the effects of various exercise protocols showed that similar protocols have relatively similar effects on the HDL and LDL levels (17).

Although the mechanism through which exercise can increase PPAR- $\alpha$ gene expression in leukocytes and macrophages is not understood, it could be attributed to the regulative effect of fatty acids on PPARs. In addition, PPARs such as LXR and RXR are also found to be nuclear receptors regulating the expression of genes that control lipid and glucose metabolism. Three isoforms of PPARs $(\alpha, \beta, \gamma)$ are expressed in metabolic tissues, heart, liver, skeletal muscle, kidney, monocytes and macrophages $(18,19)$.

PPAR- $\alpha$ activation following rehabilitation exercise might lead to over expression of key genes involved in HDL metabolism and in the reverse cholesterol transport. PPAR also speeds up the release of cholesterol from peripheral cells and facilitates the reverse cholesterol transport, thereby increasing HDL synthesis (5).

\section{CONCLUSION}

This study is the first to show that eight weeks of cardiac rehabilitation exercise increases PPAR- $\alpha$ gene expression within the lymphocytes, which is associated with plasma HDL-C levels. The results indicate that the protocols carried out in the study could be utilized for improving HDL levels and cardiovascular function in CABG patients.

\section{ACKNOWLEDGEMENTS}

This study was supported by a grant from the Islamic Azad University of Qaemshahr, Iran. The authors would like to express their gratitude to all participants in this study.

\section{CONFLICT OF INTEREST}

The authors declare that there is no conflict of interest. 


\section{REFERENCES}

1. Yancey PG, Bortnick AE, Kellner-Weibel G, de la Llera-Moya M, Phillips MC, Rothblat GH. Importance of different pathways of cellular cholesterol efflux. Arteriosclerosis, thrombosis, and vascular biology. 2003; 23(5): 712-9.

2. Rothblat GH, de la Llera-Moya M, Atger V, KellnerWeibel G, Williams DL, Phillips MC. Cell cholesterol efflux: integration of old and new observations provides new insights. Journal of lipid research. 1999; 40(5): 78196.

3. Gotto AM. Low high-density lipoprotein cholesterol as a risk factor in coronary heart disease a working group report. Circulation. 2001; 103(17): 2213-8.

4. Feige JN, Gelman L, Michalik L, Desvergne B, Wahli W. From molecular action to physiological outputs: peroxisome proliferator-activated receptors are nuclear receptors at the crossroads of key cellular functions. Progress in lipid research. 2006; 45(2): 120-59. DOI:10.1016/j.plipres.2005.12.002

5. Fruchart J-C. Peroxisome proliferator-activated receptor- $\alpha$ activation and high-density lipoprotein metabolism. The American journal of cardiology. 2001; 88(12): 24-9. doi: 10.1093/eurheartj/ehs227.

6. Von Eckardstein A, Nofer J-R, Assmann G. High density lipoproteins and arteriosclerosis role of cholesterol efflux and reverse cholesterol transport. Arteriosclerosis, thrombosis, and vascular biology. 2001; 21(1): 13-27.

7. Butcher L, Thomas A, Backx K, Roberts A, Webb R, Morris K. Low-intensity exercise exerts beneficial effects on plasma lipids via PPARF. Med Sci Sports Exerc. 2008; 40(7): 1263-70. doi: 10.1249/MSS.0b013e31816c091d.

8. Yakeu G, Butcher L, Isa S, Webb R, Roberts AW, Thomas AW, et al. Low-intensity exercise enhances expression of markers of alternative activation in circulating leukocytes: roles of PPAR $\mathrm{P}$ and Th2 cytokines. Atherosclerosis. 2010; 212(2): 668-73.

9. Leaf DA. The effect of physical exercise on reverse cholesterol transport. Metabolism: clinical and experimental. 2003; 52(8): 950-7.

10. Borg GAV. Physical performance and perceived exertion. Gleerup Lund; 1962.

11. Wei C, Penumetcha M, Santanam N, Liu Y-G, Garelnabi M, Parthasarathy S. Exercise might favor reverse cholesterol transport and lipoprotein clearance: potential mechanism for its anti-atherosclerotic effects. Biochimica et Biophysica Acta (BBA)-General Subjects. 2005; 1723(1): 124-7. DOI:10.1016/j.bbagen.2005.03.005.

12. MacNeil LG, Glover E, Bergstra TG, Safdar A, Tarnopolsky MA. The Order of Exercise during Concurrent Training for Rehabilitation Does Not Alter Acute Genetic Expression, Mitochondrial Enzyme Activity or Improvements in Muscle Function. PloS one. 2014; 9(10): e109189.

13. Tunstall RJ, Mehan KA, Wadley GD, Collier GR, Bonen A, Hargreaves $\mathrm{M}$, et al. Exercise training increases lipid metabolism gene expression in human skeletal muscle. American Journal of PhysiologyEndocrinology and Metabolism. 2002; 283(1): E66-E72.

14. Schwartz RS, Cain KC, Shuman WP, Larson V, Stratton JR, Beard JC, et al. Effect of intensive endurance training on lipoprotein profiles in young and older men. Metabolism: clinical and experimental. 1992; 41(6): 64954.

15. Park S-K, Park J-H, Kwon Y-C, Kim H-S, Yoon M$\mathrm{S}$, Park H-T. The effect of combined aerobic and resistance exercise training on abdominal fat in obese middle-aged women. Journal of physiological anthropology and applied human science. 2003; 22(3): 129-35.

16. Fatone C, Guescini M, Balducci S, Battistoni S, Settequattrini A, Pippi R, et al. Two weekly sessions of combined aerobic and resistance exercise are sufficient to provide beneficial effects in subjects with Type 2 diabetes mellitus and metabolic syndrome. Journal of endocrinological investigation. 2010; 33(7): 489-95. doi: $10.3275 / 6814$

17. Durstine JL. Effect of aerobic exercise on highdensity lipoprotein cholesterol: a meta-analysis. Clinical Journal of Sport Medicine. 2008; 18(1): 107-8. DOI:10.1001/archinte.167.10.999.

18. Francis GA, Annicotte J-S, Auwerx J. PPAR- $\alpha$ effects on the heart and other vascular tissues. American Journal of Physiology-Heart and Circulatory Physiology. 2003; 285(1): H1-H9.

19. Chinetti-Gbaguidi G, Rigamonti E, Helin L, Mutka A-L, Lepore M, Fruchart $\mathrm{J}$, et al. Peroxisome proliferator-activated receptor a controls cellular cholesterol trafficking in macrophages. Journal of lipid research. 2005; 46(12): 2717-25. 